\title{
Topology Optimization of Rotor Structure in PM Alternator
}

\author{
Deniz Perin ${ }^{1}$, Mehmet Baki Dogru² \\ ${ }^{1,2}$ ISBIR Electric Co., Department of Research and Development \\ 10150 Balikesir, Turkey \\ ${ }^{1}$ tsr16@isbirelektrik.com.tr, ${ }^{2}$ tsr03@isbirelektrik.com.tr
}

\begin{abstract}
Determining the rotor design parameters of alternator has great importance to provide the desired efficiency and magnetic flux distribution. In this paper, topology optimization of rotor structure in permanent magnet alternator is studied to provide these goals. For this purpose combinations of different diameter and height values are used to determine the optimum rotor design. Solidworks and Maxwell simulations are used for data collection. The solution of this design problem shows that how the diameter and height values affects the performance of the alternator. As a result, the efficiency of the alternator is improved under the desired magnetic flux conditions.
\end{abstract}

Keywords: alternator design, topology optimization, rotor design parameters, optimization.

\section{Introduction}

Permanent magnet (PM) generators are widely used and having low weight is a desirable feature for alternators. The topology optimization of the alternators has a possibility to obtain a desired structure for the designers. There are numerous application examples of topology optimization in the literature and topology optimization of magnetic device parameters was investigated by many researchers. For example; Batista et al [1] applied an ant colony optimization approach for the solution of the topological design of interior permanent magnet (IPM) machines. Putek et al [2] proposed a numerical approach to the topology optimization to design the PM excited machines with improved high-speed features. The shape optimization of the iron and the magnet rotor poles is provided by the combining continuum design sensitivity analysis with level set method. The novelty is the incorporation of the total variation regularization in the MLSM, which distribution is additionally modified by the gradient derivative information, in order to stabilize the optimization process and penalize oscillations without smoothing edges. Okamoto et al [3] studied on binary-based topology optimization of a high performance flux barrier for an IPM motor. Bartel et al [4] incorporated the stochastic collocation method (SCM) into a topology optimization for a PM synchronous machine with material uncertainties. The variations of the non-/linear material characteristics are modeled by the Polynomial Chaos Expansion (PCE) method. During the iterative optimization process, the shapes of rotor poles, represented by zero-level sets, are simultaneously optimized by redistributing the iron and magnet material over the design domain. Ishikawa [5] proposed optimization method combines a topology optimization method, which uses a genetic algorithm and a cleaning procedure, and a method considering ease of manufacturing. Putek [6] presented the topology optimization method to design the rotor and the tooth base in the stator of the PM excited machine with the improved high-speed features. The author is applied the modified multi-level set algorithm with the total variation to the magnetoquasistatic optimization problem. Given the eddy currents phenomenon in the model of a PM machine, the structure of a PM machine is optimized and electromagnetic losses distribution is analysed. Mizuno et al [7] proposes a topology optimization method and rotor structure designs for a PM synchronous generator using genetic algorithm. Sasaki and Igarashi [8] presented a new topology optimization of interior IPM motors using the genetic algorithm with aid of the neural network. Pastellides et al [9] presented the design optimization for four PM machines with different rotor topologies for a $2 \mathrm{~kW}$ traction application. The rotor topologies considered include the surface mount, spoke type, radial bar and v-shaped topologies. Garibaldi et al [10] presented topology optimization for surface-mounted permanent magnet motor (PMM). They reported that 3D Topology Optimization results show that the weight of a PMM rotor can be slashed by $50 \%$ without affecting its rated torque profile. Zhang et al [11] studied on the rotor iron core topology using finite element analysis (FEA). They considered influences of the iron core on the air-gap magnetic flux density, the back electro-motive-force harmonic, the cogging torque and the torque ripple were investigated. 
These studies indicate the relevance of the mechanism for topology optimization of electromagnetic devices. In this paper, topological design of the semi-embedded PM alternator is considered and it is aimed to optimize among the magnetic properties and the weight of the rotor. The rotor weight will be reduced by discharging the inside. This is performed by removing triangular slices from the rotor, and by this way gaps were formed. This will affect the magnetic flux distribution. The aim is to preserve the efficiency of this electric machine which is directly influenced from the magnetic flux. Next section describes the structure of the electric machine. Experimental results are presented in Section 3 and Conclusions are given in Section 4.

\section{Materials and Methods}

In this study $1,5 \mathrm{~kW}$ and $400 \mathrm{rpm}$ PM alternator is designed. The machine design and mechanical analysis are performed by using Solidworks, while the simulations for the magnetic flux density are performed by using Maxwell. The design parameters are given in Table 1 and 2, respectively. The structure of the alternator is presented in Fig 1.

Table 1. Rotor design parameters of alternator used for the experiments.

\begin{tabular}{|l|c|c|}
\hline Name & Unit & Value \\
\hline Inner Diameter of rotor & $\mathrm{mm}$ & 30 \\
\hline Outer Diameter of rotor & $\mathrm{mm}$ & 223 \\
\hline Length & $\mathrm{mm}$ & 40 \\
\hline Poles & units & 20 \\
\hline ThickMag & $\mathrm{mm}$ & 10 \\
\hline
\end{tabular}

Table 2. Stator design parameters of alternator used for the experiments.

\begin{tabular}{|l|c|c|}
\hline \multicolumn{1}{|c|}{ Name } & Unit & Value \\
\hline Inner Diameter of stator & $\mathrm{mm}$ & 224 \\
\hline Outer Diameter of stator & $\mathrm{mm}$ & 290 \\
\hline Length & $\mathrm{mm}$ & 40 \\
\hline Skew Width & Units & 1 \\
\hline Slots & Units & 60 \\
\hline Hs0 & $\mathrm{mm}$ & 0.9 \\
\hline Hs2 & $\mathrm{mm}$ & 9 \\
\hline Bs0 & $\mathrm{mm}$ & 2.5 \\
\hline Bs1 & $\mathrm{mm}$ & 6.5 \\
\hline Bs2 & $\mathrm{mm}$ & 6.5 \\
\hline
\end{tabular}



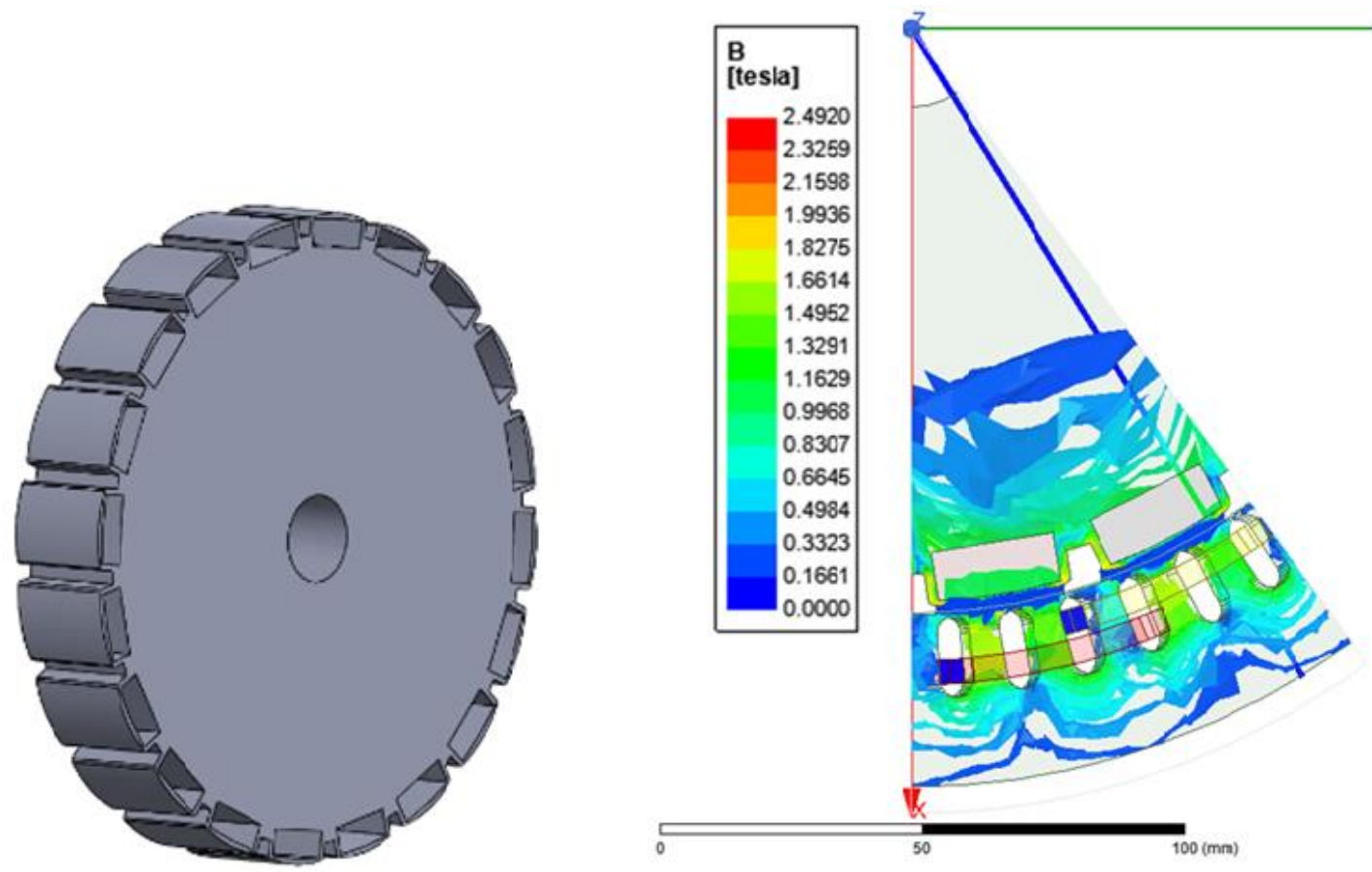

Fig. 1: Design of the current alternator.

\section{Experimental Results and Discussions}

The experimental results are presented in Table 3. In this table, combination of 3 different angles and many different discharge heights are presented as the factors. The masses, equivalent stresses, total deformations and magnetic flux values of the samples obtained as a result of Topology optimization are the responses measured by the simulations.

Table 3. Experimental Results.

\begin{tabular}{|l|l|l|l|l|l|l|}
\hline $\begin{array}{l}\text { Number of the } \\
\text { Experiment }\end{array}$ & Factors & Responses & \multicolumn{2}{l|}{} \\
\cline { 2 - 7 } & Angle & Length & Mass & $\begin{array}{l}\text { Equivalent Stress } \\
\text { (Von-Misses) }\end{array}$ & Total Deformation & $\begin{array}{l}\text { Magnetic Flux } \\
\text { Density (Tesla) }\end{array}$ \\
\hline 1 & 28 & 76.5 & 4.3545 & 38.053 & 0.0048904 & 0.53 \\
\hline 2 & 28 & 75.5 & 4.4122 & 44.429 & 0.0046516 & 0.55 \\
\hline 3 & 28 & 75.1 & 4.6367 & 28.543 & 0.0042891 & 0.58 \\
\hline 4 & 28 & 74 & 4.6644 & 29.195 & 0.0041659 & 0.56 \\
\hline 5 & 28 & 73 & 4.8319 & 30.35 & 0.0038058 & 0.44 \\
\hline 6 & 28 & 71.5 & 5.007 & 17.49 & 0.0034584 & 0.6 \\
\hline 7 & 28 & 70 & 5.1708 & 14.336 & 0.0031833 & 0.57 \\
\hline 8 & 28 & 67.5 & 5.4931 & 9.8077 & 0.0027995 & 0.57 \\
\hline 9 & 28 & 69 & 5.3087 & 11.556 & 0.0030003 & 0.58 \\
\hline 10 & 28 & 66 & 5.6386 & 9.5863 & 0.002671 & 0.6 \\
\hline 11 & 21 & 76.5 & 5.4508 & 22.861 & 0.0034406 & 0.63 \\
\hline
\end{tabular}




\begin{tabular}{|l|l|l|l|l|l|l|}
\hline 12 & 21 & 75.5 & 5.5617 & 20.73 & 0.0032155 & 0.58 \\
\hline 13 & 21 & 75.1 & 5.7474 & 22.254 & 0.0029585 & 0.61 \\
\hline 14 & 21 & 74 & 5.6962 & 19.438 & 0.0029192 & 0.59 \\
\hline 15 & 21 & 73 & 5.8344 & 20.389 & 0.0026118 & 0.59 \\
\hline 16 & 21 & 71.5 & 5.9639 & 17.023 & 0.0023589 & 0.57 \\
\hline 17 & 21 & 70 & 6.0943 & 13.847 & 0.0021523 & 0.59 \\
\hline 18 & 21 & 67.5 & 6.3631 & 9.0326 & 0.0018605 & 0.56 \\
\hline 19 & 21 & 69 & 6.2085 & 10.254 & 0.002015 & 0.58 \\
\hline 20 & 21 & 66 & 6.4609 & 8.8484 & 0.0017853 & 0.6 \\
\hline 21 & 36 & 76.5 & 3.0391 & 50.686 & 0.0083637 & 0.51 \\
\hline 22 & 36 & 75.5 & 3.2132 & 58.094 & 0.0083497 & 0.55 \\
\hline 23 & 36 & 75.1 & 3.2894 & 43.99 & 0.0085683 & 0.59 \\
\hline 24 & 36 & 74 & 3.4048 & 32.837 & 0.0082356 & 0.56 \\
\hline 25 & 36 & 73 & 3.5945 & 27.92 & 0.0080117 & 0.58 \\
\hline $\mathbf{2 6}$ & $\mathbf{3 6}$ & $\mathbf{7 1 . 5}$ & $\mathbf{3 . 8 4 0 6}$ & $\mathbf{2 1 . 9 8 7}$ & $\mathbf{0 . 0 0 7 3 7 0 6}$ & $\mathbf{0 . 5 9}$ \\
\hline 27 & 36 & 70 & 4.082 & 19.874 & 0.0067777 & 0.57 \\
\hline 28 & 36 & 67.5 & 4.5507 & 11.422 & 0.0057997 & 0.59 \\
\hline 29 & 36 & 69 & 4.2816 & 12.191 & 0.0063246 & 0.63 \\
\hline 30 & 36 & 66 & 4.6879 & 10.994 & 0.0057231 & 0.58 \\
\hline
\end{tabular}

According to the results it is clearly observed that the best design is determined by the parameters given in the 26th run. The optimum design is given in Fig 2. According to the results of the analysis the lowest weight found in the 21st trial sample. However, according to the results of Maxwell analyzes, the samples with the highest magnetic flux from the electric machine are the samples numbered 29 and 11. The results of the optimization study revealed that the geometries were analyzed by the finite element method and the yields were not observed in the structures. However, it was observed that the flow of laminations of the 21, 22 and 23 masses with the lowest masses would occur as a result of press lamination. When weight, strength and magnetic flux results are taken into consideration, optimum structure is obtained in sample number 26. 

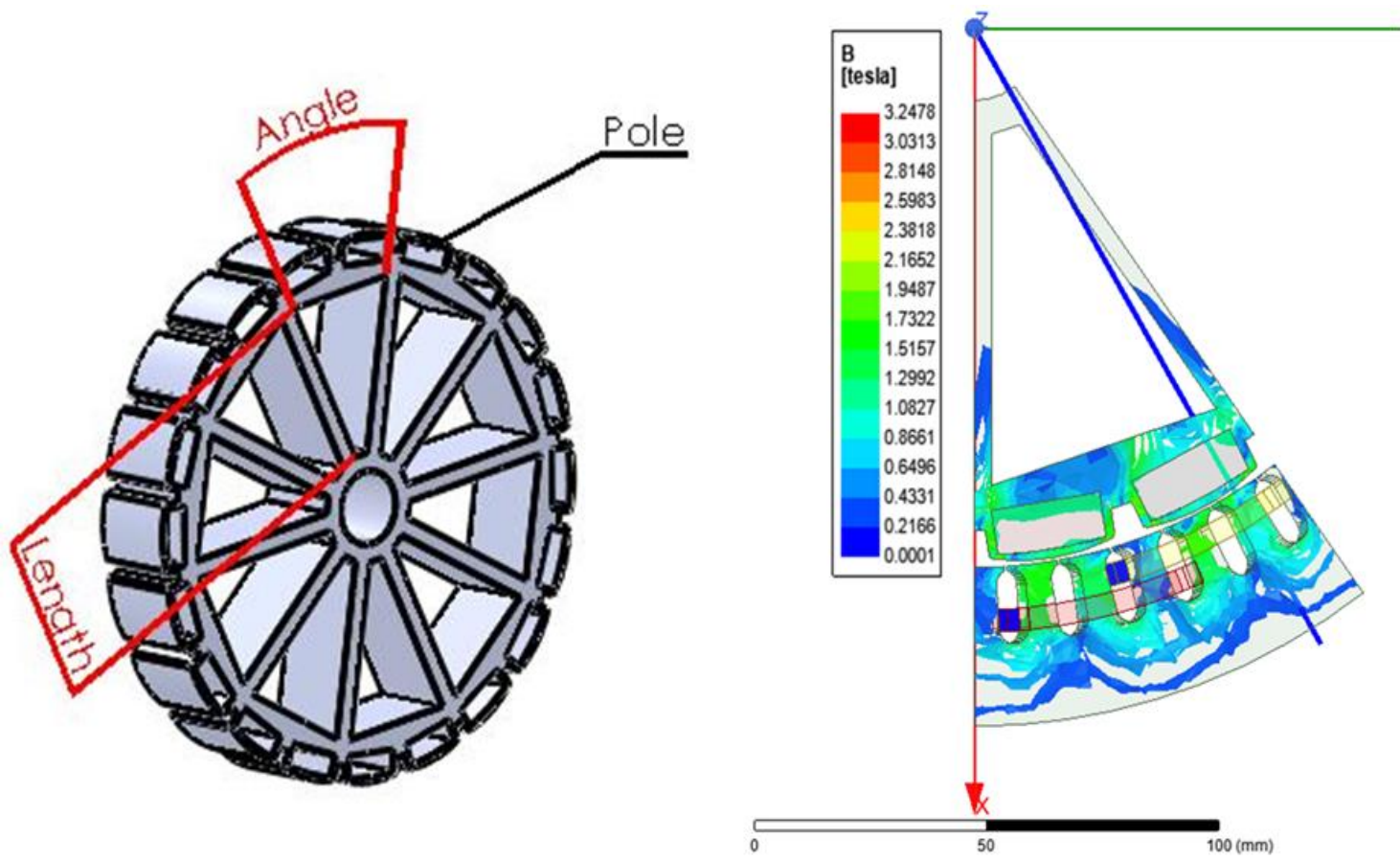

Fig. 2: Design of the optimum alternator (26 $6^{\text {th }}$ sample).

\section{Conclusion}

Several kinds of topology optimization have been proposed previously. In this study experiments performed as a practical way to address this problem. For this purpose, the performances of different design parameters performed by Solidworks and Maxwell and finally, the topology of the PM alternator has been optimized.

\section{Acknowledgements}

The authors would gratefully thank to ISBIR Electric Co. Research \& Development Department for its great support.

\section{References}

[1] L. S. Batista, F. Campelo, F. G. Guimaraes, J. A. Ramirez, M. Li and D. A. Lowther, "Ant colony optimization for the topological design of interior permanent magnet (IPM) machines", Compel-The International Journal for Computation and Mathematics in Electrical and Electronic Engineering, vol. 33, no. 3, pp. 927-940, 2014.

[2] P. Putek, P. Pablicki and R. Palka, "Topology optimization of rotor poles in a permanent-magnet machine using level set method and continuum design sensitivity analysis", Compel-The International Journal for Computation and Mathematics in Electrical and Electronic Engineering, vol. 33, no. 3, pp.711-728, 2014.

[3] Y. Okamoto, Y. Tominaga and S. Wakao, "Topology Optimization of Rotor Core Combined With Identification of Current Phase Angle in IPM Motor Using Multistep Genetic Algorithm", IEEE Transaction on Magnetics, vol. 50, No. 2, Article Number. 7017904, 2014.

[4] A. Bartel, M. Clemens, M. Gunther and E. J. W. TerMaten, "Robust Topology Optimization of a Permanent Magnet Synchronous Machine Using Multi-Level Set and Stochastic Collocation Methods", in Procedings of the 10th International Conference on Scientific Computing in Electrical Engineering (SCEE), 2014, vol. 23, pp. 233-242.

[5] T. Ishikawa, P. Xie and N. Kurita, "Topology Optimization of Rotor Structure in Permanent Magnet Synchronous Motors Considering Ease of Manufacturing", IEEJ $j$ of Industry Applications, vol. 4, no. 4, 2015.

[6] P. A. Putek, "Mitigation of the cogging torque and loss minimization in a permanent magnet machine using shape and topology optimization”, Engineering Computations, vol. 33, no. 3, pp. 831-854, 2016. 
[7] S. Mizuno, T. Ishikawa and N. Kurita, "Rotor structure design of permanent magnet synchronous generator by topology optimization method using GA", Int $J$ of Applied Electromagnetics And Mechanics, vol. 52, no. 3-4, pp.1453-1460, 2016.

[8] H. Sasaki and H. Igarashi, "Topology optimization of IPM motor with aid of deep learning", Int J of Applied Electromagnetics And Mechanics, vol. 59, no. 1, pp. 87-96, 2018.

[9] S. Pastellides, S. Gerber and R. J. Wang, "Design Strategy and Comparison of Four PM Motor Topologies for a 2kW Traction Application" in Procedings of the 27th Southern African Universities Power Engineering Conference (SAUPEC)( Jan 28-30), 2019, pp. 358-363.

[10] M. Garibaldi, C. Gerada, I. Ashcroft and R. Hague, "Free-Form Design of Electrical Machine Rotor Cores for Production Using Additive Manufacturing”, j. of Mechanical Design, vol. 141, no. 7, Article Number. 071401.

[11] G. Zhang, W. Yu, W. Hua, R. Cao, H. Qiu and A.Guo, "The Design and Optimization of an Interior, Permanent Magnet Synchronous Machine Applied in an Electric Traction Vehicle Requiring a Low Torque Ripple," Appl. Sci.", vol. 9, no. 17, pp. 3634, 2019. 